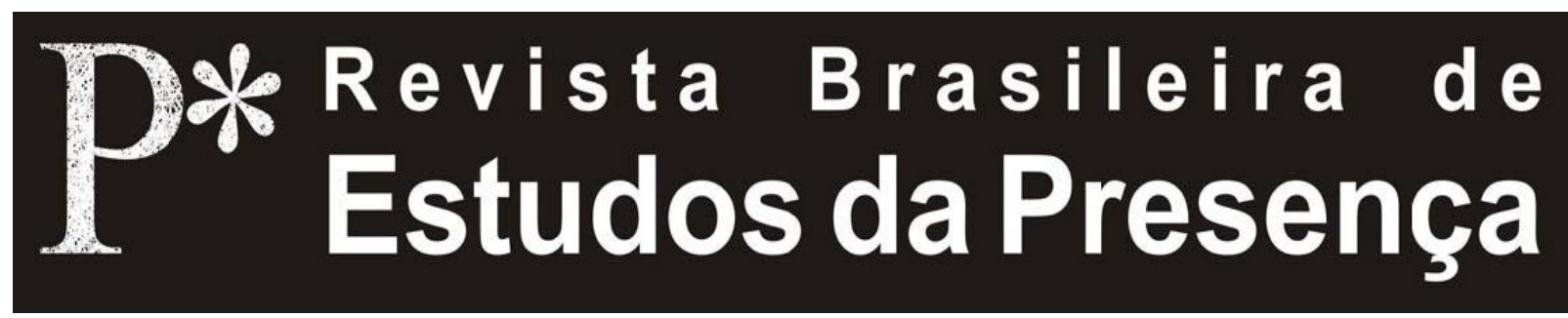

DOI - http://dx.doi.org/10.1590/2237-266021210

ISSN 2237-2660

\title{
Aonde uma Reviravolia Antropológica Poderá Levar as Ciências Humanas e as Artes
}

Hans Ulrich Gumbrecht Stanford University - Stanford, Califórnia, Estados Unidos da América

RESUMO - Aonde uma Reviravolta Antropológica Poderá Levar as Ciências Humanas e as Artes - Este trabalho discorre sobre os possíveis significados de uma chamada reviravolta antropológica no campo das Ciências Humanas. Investiga o sentido filosófico do termo antropologia e sua aplicação no campo já referido. Distinguem-se, nesse sentido, duas grandes concepções de antropologia: de um lado, como uma tentativa de determinação singular, meta-histórica e transcultural de uma definição válida do que é ser humano; e, de outro, a utilização dominante no contexto anglo-americano contemporâneo, em que um horizonte de diferentes modos de ser humano ocupa o lugar de uma concepção única. Reflete-se sobre o termo reviravolta com a qual as Ciências Humanas têm tentado pontuar e identificar aquilo que é ou deveria ser o campo do pensamento contemporâneo.

Palavras-chave: Filosofia. Antropologia. Paradigma. Ciências Humanas. Artes.

ABSTRACT - Where Could an Anthropological Turn Lead the Humanities and the Arts - This paper discusses the possible significations of a so-called anthropological turn in the field of the Humanities and Arts. The text focuses on the meaning of Anthropology and its application in these fields. In this sense, two great conceptions of Anthropology are distinguished: an understanding of Anthropology as an attempt at a singular, meta-historical and transcultural determination of a valid definition of what it means to be human; and another whose use predominates in the Anglo-American contemporary context, in which different ways of being human are considered, instead of a single conception. The text also discusses the word 'reviravolta' [overturn] which the Humanities and the Arts have been trying to point out and identify as what is or should be the contemporary thought in those fields.

Keywords: Philosophy. Anthropology. Paradigm. Humanities. Arts.

RÉSUMÉ - Vers où un Tournant Anthropologique Peut Conduire les Sciences Humaines et les Arts - Ce travail s'interroge sur les différentes significations de ce que l'on appelle le tournant anthropologique dans le champ des sciences humaines et des arts. Le texte se penche ainsi sur le sens de l'anthropologie et sur son application dans les champs déjà mentionnés. Deux grandes conceptions de l'anthropologie sont donc distinguées: celle d'une anthropologie comme la tentative de détermination singulière, métahistorique et transculturelle d'une définition valide de ce qu'est l'être humain; et celle dont l'utilisation est dominante dans le contexte anglo-américain contemporain, dans lequel un horizon de différentes manières d'être humain remplace une conception univoque. Pour finir, l'article propose une réflexion autour du mot tournant avec lequel les sciences humaines et les arts tentent de ponctuer et d'identifier ce qui est, ou ce devrait être pour ces champs, la pensée contemporaine.

Mots-clés: Philosophie. Anthropologie. Paradigme. Sciences Humaines. Arts. 
Durante as últimas décadas, muitas reviravoltas foram anunciadas ou reivindicadas dentro do círculo acadêmico das Ciências Humanas ou Humanities and Arts, como dizemos em inglês (ou dentro das Sciences humaines ou Geisteswissenschaften, ou qualquer outro termo nacionalmente específico e semanticamente mais ou menos equivalente para esse conjunto de disciplinas). Foram tantas, com efeito, que a imensa quantidade de propostas foi mais caracterizadora do passado recente do que qualquer reviravolta tomada individualmente. Creio que, até o final do século XX, uma boa parcela das reviravoltas postuladas tornaram-se paradigmas de longa ou curta duração, ao passo que, desde a virada do milênio, apenas algumas poucas chegaram a atingir um nível similar de institucionalização. A questão central para mim, no entanto, não é se esta ou aquela reviravolta proposta hoje ou no futuro terá a chance de produzir uma ampla ressonância. A questão, no presente caso, é o que uma reviravolta em direção à antropologia poderia significar para as Ciências Humanas.

Quando pergunto o que uma reviravolta antropológica pode significar para as Ciências Humanas, aludo à eclosão de um potencial cujo alcance e profundidade nos sugere imaginar consequências e possibilidades específicas. O problema é que há uma variedade de significados associados à palavra antropologia, cada um deles portando uma história particular e com uma particular carga de possibilidades acumuladas ao longo dessas histórias.

Minha principal intenção neste ensaio é distinguir e descrever esses significados e essas histórias como uma complexa rede semântica. Ao fazer isso, a distinção central será entre, de um lado, uma compreensão de antropologia como uma tentativa de determinação singular, meta-histórica e transcultural de uma definição válida do que é ser humano (junto a uma tradição de diferentes posições de resistência contra a tentativa em curso), isto é, uma definição que pode ser associada, por exemplo, com o trabalho de Immanuel Kant; e, por outro lado, uma utilização dominante no contexto anglo-americano contemporâneo do termo antropologia, em que um horizonte de diferentes modos de ser humano ocupa 
o lugar de uma concepção apenas. Os segmentos dois e três deste ensaio serão dedicados, respectivamente, a uma história do encontro de uma definição de antropologia (II) e, a outra, a uma curta história do entendimento da natureza humana como uma gama de variações (III). Começarei, contudo, com uma reflexão sobre a palavra reviravolta (entre uma série de conceitos e metáforas similares) com a qual as Ciências Humanas têm tentado pontuar e identificar aquilo que é ou deveria ser o pensamento contemporâneo para ela (I), por exemplo, quando se fala de uma reviravolta antropológica. Abandonarei, ao final (IV), a posição de um observador neutro e imparcial para tentar mostrar, baseado em dois textos tardios de Heidegger, porque o potencial da antropologia não me convence de que a mesma seja um horizonte promissor para o futuro das Ciências Humanas.

(I)

Como disse anteriormente, quem quer que fale, no mundo intelectual, de uma reviravolta, está explícita ou implicitamente levantando a questão acerca do que é o contemporâneo; mais especificamente, acerca do que é dominante no presente - para então reagir positivamente ao conteúdo da questão. Essa tendência tem sido frequentemente criticada como contraditória ao propósito das Ciências Humanas (no âmbito das diversas culturas nacionais) por serem científicas ou, pelo menos, uma instituição dedicada à produção da verdade. Será que não estaríamos cedendo a reivindicações deveras relativas das modas ao tentar identificar diferentes reviravoltas e seus resultados; ao mesmo tempo, não deveríamos esperar que a verdade fosse estável no tempo e independente dos câmbios entre diferentes contextos culturais? Minha resposta a essa questão aparentemente retórica (porém real) é um claro e redondo não. Não, porque acredito que a ambição de ser científico é potencialmente prejudicial para a contribuição potencial específica que as Ciências Humanas podem realizar. Não, também, porque eu não apenas penso que seja legítimo para elas buscar diferentes tipos de percepções em diversos momentos históricos e contextos culturais - vou ainda mais longe, inclusive, a 
ponto de afirmar que a identificação corrente do que pode ser contemporâneo é uma de nossas principais tarefas e funções.

Comparemos, contudo, o conceito autorreferencial de reviravolta com duas outras expressões de significação sobreposta, quais sejam, a de vanguarda e a de paradigma. Sempre que perguntamos o que a vanguarda pode ser, ou onde ela pode estar, estamos procurando por aquelas posições, conteúdos e afirmações dentro de um determinado quadro intelectual, com grandes chances de se tornarem dominantes no futuro, ainda que não o sejam necessariamente por hora. É minha impressão, por exemplo, que grande parte do trabalho intelectual realizado pelo New Literary Observer vai na direção da identificação da vanguarda. Por outro lado, quando falamos de paradigmas, estamos nos referindo a algo que é hoje dominante e pertencente, também, a um determinado quadro institucional. A história das Ciências Humanas, durante a maior parte da segunda metade do século XX, pode ser narrada quase como uma sequência linear desses paradigmas bem circunscritos, ao passo que a atual cena parece mais uma acumulação, por vezes confusa, de paradigmas diferentes e antagônicos (ou apenas justapostos, por vezes). Quando, contudo, falamos de uma reviravolta (linguística, visual, antropológica, para mencionar apenas algumas), assumimos o postulado ainda mais abrangente de que, por razões epistemológicas, a estrutura institucional e as promessas intelectuais sobre cujo fundamento as diferentes disciplinas acadêmicas colaboram devem agora mudar. Se é verdade que hoje em dia tendemos a falar mais de reviravoltas do que propriamente de paradigmas, talvez isso tenha a ver com a impressão de que a constante produção de novos paradigmas (tal como foi característico para as Ciências Humanas entre as décadas de 1950 e 1990, aproximadamente) tenha estacionado e que essa situação exija uma grande revisão. Sendo assim, por definição, reivindicar, sugerir ou anunciar uma reviravolta, no mundo acadêmico, significa afastar-se daquilo que tinha sido a estrutura institucional até então.

(II)

A palavra antropologia, não por acaso, creio eu, é um produto do século XVII, e tem tenazmente conseguido manter-se 
viável até os dias atuais, a despeito de uma tradição igualmente tenaz de resistência e crítica. Quero, assim, traçar sua história, ou seja, seu processo de formação como uma complexa estrutura semântica com um potencial programático específico; dividirei, por conseguinte, a narrativa desse processo em sete etapas. O século XVII parece ter sido o período histórico a partir do qual qualquer tipo de reflexão dependente do Gênesis e da ideia do mundo como criação divina sobre o que é e o que significa ser humano deixou de ser padrão. Ao mesmo tempo, foi a grande era da teologia negativa para a qual a distância entre Deus e o mundo humano e a experiência de que Ele não mais falaria aos seres humanos (ou, alternativamente, de que Ele nunca tivesse falado com os mesmos) tornou-se, de maneira realmente paradoxal, prova de Sua existência e também condição geral para encontrar orientação individual e coletiva no que concerne às especulações sobre Sua vontade. Durante esses anos, e em resposta a essas novas questões, René Descartes formulou sua singular e bem sucedida definição e identificação da (ontologia da) existência humana baseada exclusivamente (este advérbio é, evidentemente, crucial) na capacidade de pensar de nossa consciência. Com a frase "Penso, logo existo", a existência humana torna-se, em grande parte, coextensiva à sua capacidade de pensar (Poder-se-ia dizer até: com a impossibilidade de os seres humanos pararem de pensar). Pode-se dizer, assim, que o "Cogito" cartesiano seria a condição histórica para o surgimento do conceito e da concepção de antropologia e por seu evidente potencial inspirador de concepções filosóficas programáticas.

Como uma segunda etapa de nossa narrativa - portanto, em um momento ainda inicial - e, claramente, em resposta a um tipo de autorreferência humana baseada exclusivamente na mente (isto é, cartesiana), começa a surgir uma fascinação com a materialidade da vida humana que nunca chegou a nos abandonar completamente. Em meados do século XVII, essa tendência já havia alcançado sua expressão no Materialismo de Pierre Gassendi, o qual reagiu ao impacto desmaterializador da filosofia cartesiana. Cem anos depois, um pensador como Denis Diderot estava obcecado pela questão de que se os sentidos, como parte do corpo humano, seriam capazes de transmitir 
uma imagem adequada de cada um dos diferentes ambientes da existência humana. A partir desse momento, a antropologia se desdobrou numa tensão de complexidade crescente entre concepções da vida humana baseadas no corpo, de um lado, e na mente, de outro; o surgimento da estética filosófica, no século XVIII, com sua atenção focada na relação sensual com o mundo, foi também parte desse desenvolvimento.

De forma implícita, e como uma terceira etapa, a antropologia já tinha nesse momento passado de uma preocupação ontológica concernente ao que era ser humano, problemática central no século XVII, para uma reflexão epistemológica sobre a capacidade de seu aparato cognitivo (isto é, sobre a capacidade do sujeito) para assimilar o mundo exterior dos objetos. É exatamente essa constelação que prepondera nos escritos críticos de Immanuel Kant. Ainda que sua ambição tivesse sido demonstrar que a existência humana era, de fato, capaz de realizar a tarefa de produzir uma imagem adequada do mundo exterior, houve importantes leituras de sua obra que se concentraram nas eventuais dificuldades com que Kant se debateu ao tentar realizar esse intento (e argumentaram que tais dificuldades fazem dele um dos primeiros filósofos que eram céticos a esse respeito, o que é, portanto, a verdadeira razão de sua importância sistemática até hoje).

Michel Foucault, sobretudo em sua obra-prima Les mots et les, de 1966, afirmava que a topologia epistemológica básica do Sujeito e Objeto do século XIX tornou-se a estrutura básica da forma institucional das Sciences humaines, isto é, para um conjunto de disciplinas acadêmicas nas quais uma autorreferência humana de tipo cartesiano tornou-se, paradoxal e inevitavelmente, tanto o sujeito como o objeto da reflexão. Essa constitui a quarta etapa na história da antropologia. No final do século XIX desapareceu muito rapidamente, pelo menos entre os intelectuais, a esperança de que o aparato cognitivo do Sujeito pudesse garantir de fato uma complexa e suficientemente precisa interpretação do mundo exterior. Esse pode ser visto como o quinto capítulo da história da antropologia.

Houve múltiplas tentativas de concentrar-se, de uma maneira autorreflexiva, sobre a estrutura da cognição huma- 
na, com a promessa de descobrir, por diferentes meios e com resultados variáveis, quais traços em nossa(s) imagem(ens) do mundo eram efeitos do inevitável experienciar o mundo por meio da perspectiva do Sujeito. Referimo-nos, pelo termo Fenomenologia, a diferentes versões desse projeto filosófico (cujos pais intelectuais foram Edmund Husserl e Henri Bergson). No início do século XX, então, um novo nível de reflexão acerca da constituição do Sujeito e do impacto desse conhecimento na maneira como os seres humanos referem-se a si próprios produziu duas concepções específicas de antropologia que, de fato, tomariam este mesmíssimo nome para si mesmas. Elas constituem o sexto capítulo de nossa narrativa.

De um lado, há uma descrição geral e altamente abstrata de diferentes estruturas e ferramentas cognitivas as quais se acredita serem partilhadas por todos os seres humanos. Dentro da tradição husserliana são chamadas de sujeito transcendental ou mundo da vida, denominação esta que coloca mais ênfase naquilo que elas fazem o mundo parecer. Finalmente, a concepção do mundo da vida desembocará na convicção do hoje chamado Construtivismo, segundo o qual é suficiente para grupos de seres humanos partilharem visões de mundo (construções sociais da realidade), a despeito do fato dessas visões de mundo coincidirem ou não com qualquer realidade fora da mente humana. Outra concepção, cultivada e desenvolvida especificamente por filósofos alemães durante os anos vinte, deu-se a si própria o nome de Antropologia Humana. Ela parte da concepção de que os humanos, se comparados aos animais, são criaturas que perderam seus instintos primários (o substantivo alemão é Maengelwesen), e que a sociedade e a cultura são dimensões que atuam de modo a compensar essa perda. Finalmente, tanto o Construtivismo quanto a $A n$ tropologia Humana sobreviveram como opções filosóficas viáveis (ainda que dificilmente surpreendentes) até os dias atuais, servindo de base, além disso, para uma série de novos desenvolvimentos. A Antropologia Literária de Wolfgang Iser, por exemplo, tentou demonstrar como a leitura da literatura era uma atividade que desafiava, e que, por meio do desafio, levava adiante o desenvolvimento das capacidades especificamente humanas da mente e da cognição. 
Durante a segunda metade do século XX, entretanto, uma crítica cada vez mais agressiva (e crescentemente convincente) de tais conceitos altamente abstratos como o de antropologia (no sentido tradicional, predominantemente alemão), de sujeito transcendental ou mundo da vida, provocou a emergência de uma concepção profundamente diferente de antropologia. O primeiro livro no qual Jacques Derrida desenvolveu uma posição filosófica independente (La voix et le phénomène, de 1967), foi uma crítica à premissa central sobre a qual a Fenomenologia, desde o final do século XIX, havia fundamentado o projeto de uma descrição completa das características gerais da mente humana e/ou do aparato cognitivo humano. A própria crença de que uma tal descrição seria possível, argumentava Derrida, baseava-se na analogia extremamente discutível que se supunha existir entre o que podemos chamar auto-observação mental, isto é, a auto-observação e autodescrição da consciência humana (que nunca pode ser completa, segundo ele) e a impressão humana de que é perfeitamente possível ouvir a si próprio falar. Houve uma crítica diferente, mais politicamente motivada, que acabou originando resultados semelhantes - e foi a crítica que salientou como a pretensão de haver reconstruído as características gerais da existência humana eram sempre perpassadas, pré- e inconscientemente, por configurações culturais muito mais específicas (sobretudo as perspectivas do branco e do homem e seus preconceitos), que acabariam sendo impostas, com peso e pretensões normativas, a pessoas e grupos que haviam se criado sob visões de mundo diferentes.

A convergência de ambas as críticas acabou dando origem a uma concepção diversa de antropologia, em que o principal desafio de qualquer observação era, ao invés da identificação de características gerais da existência humana, isto sim, trazer à tona a diferença cultural (de gênero, étnica), de tal modo que o projeto da antropologia deslocou-se de uma perspectiva transcendentalista em direção ao desenvolvimento de um conceito mais complexo do que é ser humano, um conceito no qual a variação e a diferença intrínsecas substituem o 
padrão de um denominador comum. Desenvolver e aumentar tal variedade é a ambição principal da moderna Antropologia Cultural, especialmente dentro dos círculos acadêmicos anglo-americanos. Proveniente da tradição teológica judaica e inspirado por várias posições da filosofia francesa do século XX, Emmanuel Lévinas desenvolveu uma concepção similar da vida humana como variedade, na qual o grau de variação vai muito mais além (e que é motivada antes eticamente que epistemologicamente). Para Lévinas, é a irredutível dignidade da individualidade humana, tal como aparece em cada rosto individual, que as sociedades e as culturas deveriam proteger.

Deveria ser óbvio que nem o estilo da Antropologia Cultural atual e sequer a concepção levinasiana de existência humana permitiriam chegar às generalizações e ao nível da abstração conceitual que foram associadas, na Alemanha e na Rússia, por exemplo, à noção e à autorreferência normativa de ser cientifico, um pouco obsessivamente, talvez.

(IV)

Martin Heidegger, em seu texto O princípio da Razão, originalmente uma preleção realizada em Freiburg nos anos cinquenta do século passado, fornece um argumento contrário à concepção de antropologia como uma noção monolítica. Esse argumento é semelhante à crítica de Derrida - porém, mais abrangente, e, se a palavra ainda for de algum modo, tolerável, muito mais radical em suas consequências. Ao tentar desafiar o paradigma sujeito-objeto como uma premissa aparentemente necessária, em favor de suas próprias noções de desvelamento do ser e de história do ser, em que a iniciativa da produção da verdade não se assenta nos seres humanos, Heidegger pergunta como nós, isto é a tradição filosófica ocidental, poderíamos ter nos convencido de que o aparato cognitivo humano seria suficientemente equipado para uma adequada autodescrição e, baseado nessa e em muitas outras descrições, suficientemente equipado para desenvolver estratégias que garantiriam nossa sobrevivência individual e coletiva. A resposta é que tal otimismo tinha provindo da imagem e do conceito de um Deus monoteísta (onisciente e todo-poderoso), que havia precedido 
a autorreferência humana como um Sujeito, própria do início da Idade Moderna.

$\mathrm{Na}$ Carta sobre o Humanismo, de 1947, o primeiro texto publicado por Heidegger após o fim da Segunda Guerra Mundial, o filósofo reage à pergunta do francês Jean Beaufret, seu colega e admirador, acerca de que modo ele acreditava ser necessário revisar o conceito de ser humano à luz da situação do pós-guerra. Também nesse caso Heidegger reage, criticando a própria questão - ao invés de respondê-la. Pois perguntar o que é ser humano, diz Heidegger, leva inevitavelmente a uma comparação entre humanos e animais e, com isso, a uma perspectiva epistemológica básica que ele considera superficial e inadequada. Animais dependem tão somente de sua percepção e orientação dentro da natureza, como sendo um ambiente primário. Essa situação implica e define uma estrutura bipolar, pois subjaz ao paradigma sujeito/objeto. De outro lado, a posição epistemológica específica da e reservada à existência humana (Dasein), de acordo com Heidegger, é aquela do ser $a i$, não no papel de um destinatário, mas como o catalisador necessário para o autodesvelamento do Ser. Com o Ser, estou convencido, Heidegger pretende referir-se a algo substancial e individual (certamente não a um conceito abstrato). É o Ser, por assim dizer, que toma a iniciativa de desvelar-se a si mesmo, o que significa que o Ser se mostra independentemente de qualquer perspectiva específica (dito de outro modo, ele vem à tona como uma coisa em si). Enquanto o desvelamento do Ser não deveria ser algo semelhante a uma mensagem dirigida aos seres humanos, não poderia acontecer sem a presença do Dasein. Finalmente, uma vez que o Ser desvela-se a si mesmo, ele torna-se o destino (Geschick) do Dasein, ou seja, baseado em outro jogo de palavras (o jogo entre as palavras Geschick e schicken - que significa enviar), Heidegger sugere que o Ser supera, molda e determina as vidas individuais humanas e ao mesmo tempo a história e o destino dos seres humanos.

Não estou preocupado em explicar e muito menos em aceitar cada detalhe da complexa intuição de Heidegger em relação ao lugar epistemológico da existência humana. Ela evoca, contudo, ou forma, ao menos, um quadro mais amplo dentro 
do qual eu gostaria que as Ciências Humanas divisassem a si próprias e desenvolvessem uma visão mais atual do que podem fazer, em vez de apoiarem-se em uma noção singular e monolítica ou ainda em uma noção intrinsecamente plural de antropologia. Como premissa, tenho esperança de que as Ciências Humanas pratiquem um pensamento arriscado, por trás dos muros de suas torres de marfim (sim, estou tentando tornar a recorrente conotação negativa dessa metáfora em uma apreciação de seu espaço como sendo protegido). Esperaria, ainda, que as Ciências Humanas praticassem todos os tipos de pensamento que não podem ter lugar nos contextos do cotidiano porque acarretam o risco de seu congestionamento ou de desvio das vias de seu funcionamento normal. Nesse espírito, as Ciências Humanas não precisam definir e sequer deveriam tentar definir o que são seus campos temáticos específicos ou seus horizontes próprios de problematização, mas deveriam, isto sim, abrir-se para todos os problemas que se lhes apresentam com surpreendente frequência e de modo iniludível como sendo problemas para serem pensados profundamente problemas inevitáveis e que trazem consigo riscos demasiado altos para que se possa lidar com eles (e pensá-los de modo sistemático e profundo) no dia a dia. Em outras palavras, ao invés de inventar agendas de pesquisa que necessitam ser atualizadas e redesenhadas a cada par de anos, penso que as Ciências Humanas deveriam estar abertas para contemplar (na verdade, eu gostaria que o conceito e a atitude de contemplação substituíssem o conceito de investigação), para afeiçoar-se a, para pensar profundamente quaisquer coisas que se nos apresentem como problemas demasiado complexos e arriscados para nossas racionalidades cotidianas usuais. Não estamos tentando pensar o Holocausto e o Gulag profundamente porque esperamos desenvolver novas estratégias sociais ou políticas ou mesmo valores (e muito menos aparatos técnicos) deste modo; fazemos isso porque não podemos evitá-lo, porque a memória do Gulag e do Holocausto ainda nos assombra, porque não fomos capazes de abandonar essa memória atrás de nós. Da mesma forma, mas pelo lado positivo, não lidamos com certos textos (aqueles a que chamamos de clássicos) só porque 
decidimos fazê-lo, mas, sobretudo, porque nos afeiçoamos a eles, em uma relação de enriquecimento e carinho existencial.

Meu ceticismo em relação a uma possível reviravolta antropológica nas Ciências Humanas não é sinônimo, de modo algum, de um ceticismo em relação à intuição (e mesmo, às vezes, à nervosidade e à irritabilidade intelectuais) que parece anunciar a necessidade e o anseio por uma reviravolta. Em princípio, tais sentimentos e desejos por mudança nunca deveriam ser colocados em parênteses ou represados porque (utilizando, mais uma vez, a linguagem estilisticamente pesada de Heidegger) eles podem anunciar situações e momentos em que o Ser desvela-se a si mesmo (eventos da Verdade, como Heidegger também os chama). Fazer uma promessa por uma reviravolta antropológica é uma forma de reagir àquilo que poderia ser a aura, a antecipação de uma mudança tão radical e que vem como um evento da Verdade - mas acredito que isso é sobremaneira programático, demasiadamente deliberado, não paciente, aberto e suficientemente precário. Obviamente, eu posso estar errado. 


\section{Nota}

${ }^{1}$ Esta é uma tradução que inevitavelmente simplifica o título original Der Satz von Grund que joga com o duplo sentido da palavra alemã Grund, isto é, fundamento e razão.

Hans Ulrich Gumbrecht é filósofo com doutorado em Filosofia pela Universität Konstanz, na Alemanha. É professor no Departamento de Literatura Comparada da Stanford University, nos Estados Unidos. Foi, também, professor associado na Université de Montréal, no Canadá; diretor de estudos associado na École des Hautes Études en Sciences Sociales e professor convidado no Collège de France, em Paris. É membro da American Academy of Arts \& Sciences e tem livros e artigos publicados em diversas línguas.

E-mail:sepp@stanford.edu

Traduzido do original em inglês por Marcelo de Andrade Pereira e revisado por Elaine Padilha Guimarães. 